\title{
LRRK2 G2019S in the North African Population: A Review
}

\author{
Hani T.S. Benamer ${ }^{a}$ Rajith de Silva ${ }^{b}$ \\ a Department of Neurology, New Cross Hospital, Wolverhampton, and bepartment of Neurology, \\ Essex Centre for Neurological Sciences, Queen's Hospital, Romford, UK
}

\section{Key Words}

North Africa $\cdot$ Parkinson's disease $\cdot$ LRRK2

\begin{abstract}
Parkinson's disease (PD) is a common neurodegenerative disorder, for which environmental and/or genetic factors are postulated as possible causes. Over the past decade there has been a substantial increase in the knowledge of the genetics of PD. Mutations in Leucine-rich repeat kinase 2 (LRRK2) are the most frequent genetic causes of PD, and the common G2019S mutation has been identified in various ethnic groups with variable frequency. The aim of this article is to review the literature relating to LRRK2 G2019S in the North African population, which is composed of two main ethnic groups - the Berbers and the Arabs. The frequency of $L R R K 2$ G2019S is $30-41 \%$ in familial PD and $30-39 \%$ in apparently sporadic PD in North Africa. Within healthy controls, Moroccan Berbers appear to have the highest carrier frequency at $3.3 \%$. The majority of the available studies do not draw a clear distinction between the two ethnic groups, despite the distinct possibility that their ancestral origins are different. Further research looking at the respective prevalences of LRRK2 G2019S in Berbers and Arabs, and in different Arab populations, seems justified.

Copyright $\odot 2010$ S. Karger AG, Basel
\end{abstract}

Parkinson's disease (PD) is a neurodegenerative disorder which affects up to $2 \%$ of individuals older than 65 . Its aetiology is for the most part not known, although interplay between genetic and environmental factors is frequently postulated. Since 1997, mutations in six genes have been associated with forms of parkinsonism resembling idiopathic PD with dominant and recessive modes of transmission. Of these, mutations in Leucine-rich repeat kinase 2 (LRRK2, also referred to as PARK8) are the most common, accounting for around $4 \%$ of all familial cases worldwide. Inheritance of LRRK2 is dominant and penetrance is age-dependent. The mutation $6055 \mathrm{G} \rightarrow \mathrm{A}$ which causes a Gly2019Ser change represents a 'hot spot' in $L R R K 2$, and has been reported from more than 20 different populations, accounting for between 36 and $<1 \%$ of their respective hereditary cases [1]. Due in part to its variable penetrance, G2019S mutations can also account for up to $39 \%$ of apparently sporadic cases of PD. The aim of this article is to review the literature relating to LRRK2 G2019S in the North African population specifically and to discuss the potential for further research.

\section{KARGER}

Fax +4161306 1234 E-Mail karger@karger.ch www.karger.com
Hani T.S. Benamer

Department of Neurology, New Cross Hospital

Wolverhampton WV10 0QP (UK)

Tel. +44 1902695 055, Fax +44 1902695631

E-Mail benamer@ doctors.org.uk 
Fig. 1. The five North African countries (in dark grey).

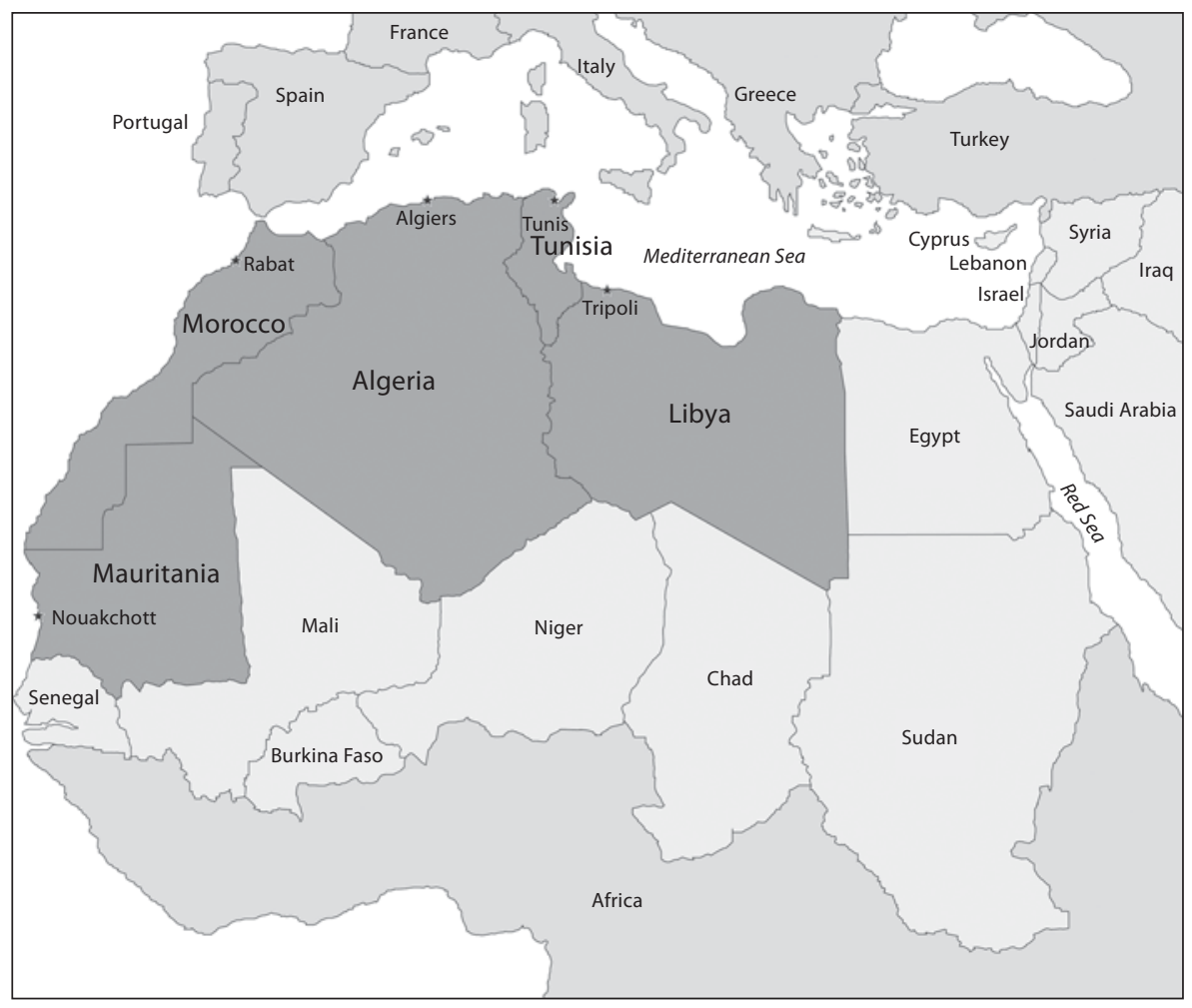

\section{North African Population}

North Africa in defined as the geographical area west of the Nile valley to the Atlantic Ocean. The area is separated from sub-Saharan Africa by the Great Sahara and from Europe by the Mediterranean Sea (fig. 1). Politically, it encompasses five countries: Libya, Tunisia, Algeria, Morocco and Mauritania (Maghreb countries). Egypt meanwhile is usually regarded as part of the Middle East. The five Maghreb countries have a population of around 75 million. The North African population has two major ethnic groups: the Berbers and the Arabs. The Berbers, also called the Imazighen (the free men), are indigenous to North Africa with a history extending back to the 7th century BC. The Arabs arrived in the region as part of the Muslim army that conquered the North African region in the 7th century AD. It took almost four centuries for both 'Islamization' and 'A rabization' of the region to take place. The emigration of two major Arabic/Muslim tribes (Banu Hilal and Banu Salam) to North Africa in the 11th century AD had a lasting and permanent effect on the composition of the population. Therefore, a good number of the modern North African population who call themselves 'Arabs' are Berbers, in origin. Nevertheless, the Berber culture and language survive to this day as some parts of the Berber population restricted their intermixing and intermarriage with Arabs to preserve their ethnicity. The estimated number of Berbers in current North Africa is around 20 million, living mainly in Algeria (20\% of the population), Morocco (40\% of the population) and a small minority in Tunisia and Libya (probably between 1 and $5 \%$ of these populations) [2].

\section{LRRK2 G2019S in the North African Population}

Various studies have shown that the frequency of LRRK2 G2019S in North African populations is 30-42\% in familial PD [3-6] and 30-34\% in apparently sporadic PD $[6,7]$. Recently the international $L R R K 2$ consortium reported a worldwide frequency of $1 \%$ of $L R R K 2$ G2019S in 'sporadic' PD and $4 \%$ in familial PD, with the highest frequency of LRRK2 G2019S being observed in 'North African Arabs' (39\% of sporadic and 36\% of familial PD), consistent with the earlier observations [1]. Ashkenazi Jews showed respective frequencies of 10 and $28 \%$, and constituted the next most common ethnic group [1]. The 
Table 1. Frequency of $L R R K 2 \mathrm{G} 2019 \mathrm{~S}$ in the North African population

\begin{tabular}{|c|c|c|c|c|c|}
\hline \multirow{2}{*}{$\begin{array}{l}\text { Reference } \\
\text { (first author) }\end{array}$} & \multirow[t]{2}{*}{ Year } & \multirow[t]{2}{*}{ Population } & \multicolumn{3}{|c|}{ Frequency of G2019S mutation } \\
\hline & & & familial PD & $\begin{array}{l}\text { apparently } \\
\text { sporadic PD }\end{array}$ & healthy volunteers \\
\hline Lesage [4] & 2005 & Moroccan, Algerian and Tunisian & $7 / 17,41 \%$ & - & $0 / 82,0 \%$ \\
\hline Lesage [3] & 2006 & North African Arabs & $3 / 10,30 \%$ & - & $2 / 69,2 \%$ \\
\hline Ishihara [5] & 2007 & Tunisian & $39 / 91,42 \%$ & - & - \\
\hline Hulihan [7] & 2008 & Tunisian & - & $72 / 238,30 \%$ & $7 / 371,2 \%$ \\
\hline Healy [1] & 2008 & North African Arabs & $51 / 143,36 \%$ & $22 / 56,39 \%$ & $4 / 739,<1 \%$ \\
\hline Change [10] & 2008 & Moroccan, Algerian, Tunisian and Libyan & - & - & $13 / 597,2.2 \%$ \\
\hline Lesage [6] & 2008 & Moroccan, Algerian, Tunisian and Libyan & $7 / 17,41 \%$ & $40 / 119,34 \%$ & $1 / 66,1.5 \%$ \\
\hline
\end{tabular}

frequency is higher in southern European countries (varying between $2-4 \%$ in sporadic and $3-14 \%$ in familial PD) than in Northern European countries (between $<1-$ $2 \%$ in sporadic and $0-3 \%$ in familial PD) [1]. The LRRK2 G2019S is rare in Asian countries such as China, Japan, Korea and India $(<0.1 \%)$, and is reported in the white North American population at a frequency of $1 \%$ in sporadic and $3 \%$ in familial PD [1].

Clinically, patients with mutations in LRRK2 were thought to present with classic features of parkinsonism indistinguishable from idiopathic PD and with a similar age of onset [8]. Emerging data, however, seem to suggest that patients with the LRRK2 G2019S mutation from North Africa have a more severe motor phenotype, and especially more dyskinesias and drug-induced dyskinesias $[6,9]$. In the study by Lesage et al. [6], levodopa-associated dyskinesias were more evident in G2019S carriers than in non-carriers, even after correction for (longer) treatment duration. These observations, if validated, may have diagnostic and therapeutic implications for clinical practice, as well as providing insights into the biological mechanisms underlying drug-induced motor complications. The LRRK2 G2019S mutation was found to be more frequent in healthy North African subjects (2.2\%), compared with $0.2 \%$ in France and $0.6 \%$ Spain [10]. The relative frequencies were $1.3 \%$ in Libyans, $1.7 \%$ in Tunisians, $2.1 \%$ in Algerians, $2 \%$ in Moroccans, and 3.3\% in Moroccan Berbers [10], suggesting that LRRK2 G2019S could be more common in the Berber populations of North Africa than in Arabs. However, the same mutation of $L R R K 2$ is also present at a relatively high frequency in Ashkenazi Jews (up to $30 \%$ of familial PD and up to $13 \%$ in apparently sporadic PD), implicating a common founder effect for the mutation possibly dating back to the 13th century
[11]. Alternatively, two separate founding events (coinciding with the Jewish diaspora some 2,250 years ago (586 $\mathrm{BC}$ to $70 \mathrm{AD}$ ) have been proposed [12]. A founding haplotype shared by individuals from Tunisian, North American, European and Middle Eastern countries has been identified [13].

The lifetime penetrance of PD in Tunisian LRRK2 G2019S carriers is estimated to be 45\% [7]. This probably applies to the all North African populations. Authors (in Western countries) have queried whether testing for LRRK2 G2019S should be offered 'routinely' to patients with PD from North African countries. Such an approach will have significant medical genetics implications, and the acceptability of such testing to these populations is also unknown.

A summary of the studies of the frequency of LRRK2 G2019S in the North African population is shown in table 1 .

\section{Could LRRK2 G2019S Help in Determining the Origin of the North African Population?}

It is worth noting that studies to date on the presence of LRRK2 G2019S in North Africa have not made a clear distinction between Berbers and Arabs [3-5, 7]. The international LRRK2 consortium study described the pertinent population as 'North African Arabs' [1]. It is not clear whether they are excluding Berbers or, for the sake of simplicity, referring to the entire population as Arabs. The same criticism applies to the papers by Lesage et al. $[3,4]$, although they stated that the studied population originated from Morocco, Algeria and Tunisia. Hulihan et al. [7] looked at LRRK2 G2019S in apparently sporadic 
PD in Tunisia and called the studied population 'ArabBerber' without a clear demarcation between the two. Taking into consideration that only $1 \%$ of the Tunisian population are Berbers [2], it could be assumed the majority of the patients who were studied are Arabs by default. On the other hand, Change et al. [10] reported a higher frequency of LRRK2 G2019S in Moroccan Berbers, in comparison with other North African populations. However, their study did not clearly state whether the other North African populations were Arabs, Berbers or a mixture of both. Therefore, it will be premature to draw any firm conclusions until there is a study that clearly distinguishes between the two main ethnic groups in North Africa.

There is no agreement about the origin of the Berbers and this issue has eluded historians, anthropologists, archaeologists and geneticists. There are several theories and hypotheses. One suggests that Berbers are native to North Africa and that their ancestors were the Homo sapiens who founded European populations, including the Saami of Scandinavia [14]. The low frequency of $L R R K 2$ G2019S in Europe does not appear to support an association between (especially northern) European and Berber populations, although the mutation could have arisen de novo after a point of divergence. Other studies have shown genetic associations between Yemeni people (from the Arabian Peninsula) and Berbers, and therefore a very likely common origin [15]. Finally, studies have also indicated genetic similarities between Arabs and Berbers in North Africa [16, 17], implying either that Berbers are of Arabic origin or that the people who call themselves Arabs in North Africa were originally Berbers (Arabization of Berbers). Meanwhile, Farrer et al. [18] recently suggested that LRRK2 G2019S could be of Phoenician origin, rather than Arabic, dating back to the founding of Carthage in $814 \mathrm{BC}$.

The crucial first question that needs to be resolved is how frequently LRRK2 G2019S occurs in North Africa in populations calling themselves 'Arabs' as opposed to 'Berbers'. The second would be to determine the relative frequency of this mutation in other Arab populations, namely in Lebanon and Syria, to further investigate Farrer's 'Phoenician hypothesis' [18]. Estimating its prevalence in the Arabian Peninsula (mainly Saudi Arabia and Yemen) may inform the argument on whether Berbers are of Arab origin or not. In any event, this research may shed considerable light on the ongoing discussion about the origins of the North African population(s).

\section{Conclusion}

Research to date has revealed a very high prevalence of the LRRK2 G2019S mutation in North Africa, implicating a significant monogenic contribution to the causation of PD in this population. Further studies looking at the relative frequency of this mutation in the Berbers and Arabs of North Africa, and its prevalence in other Arab countries such as Lebanon, Syria, Saudi Arabia and Yemen, seem warranted. These may further enhance our understanding of the genetic contribution to the causation of $\mathrm{PD}$, as well as possibly casting light on the origins of the peoples of North Africa.

\section{References}

1 Healy DG, Falchi M, O’Sullivan SS, Bonifati V, Durr A, Bressman S, et al: Phenotype, genotype, and worldwide genetic penetrance of LRRK2-associated Parkinson's disease: a case-control study. Lancet Neurol 2008;7: 583-590.

2 Brett M, Fentress E: The Berbers. Oxford, Blackwell, 1997.

- 3 Lesage S, Durr A, Tazir M, Lohmann E, Leutenegger AL, Janin S, Pollak P, Brice A: LRRK2 G2019S as a cause of Parkinson's disease in North African Arabs. N Engl J Med 2006;354:422-423.
4 Lesage S, Ibanez P, Lohmann E, Pollak P, Tison F, Tazir M, et al: G2019S LRRK2 mutation in French and North African families with Parkinson's disease. Ann Neurol 2005; 58:784-787.

5 Ishihara L, Gibson RA, Warren L, Amouri R, Lyons K, Wielinski C, et al: Screening for LRRK2 G2019S and clinical comparison of Tunisian and North American Caucasian Parkinson's disease families. Mov Disord 2007;22:55-61.

-6 Lesage S, Belarbi S, Troiano A, Condroyer C, Hecham N, Pollak P, et al: Is the common LRRK2 G2019S mutation related to dyskinesias in North African Parkinson disease? Neurology 2008;71:1550-1552.
7 Hulihan MM, Ishihara-Paul L, Kachergus J, Warren L, Amouri R, Elango R: LRRK2 Gly2019Ser penetrance in Arab-Berber patients from Tunisia: a case-control genetic study. Lancet Neurol 2008;7:591-594.

$\checkmark 8$ Healy DG, Wood NW, Schapira AH: Test for LRRK2 mutations in patients with Parkinson's disease. Pract Neurol 2008;8:381-385.

9 Nishioka KMP, Kefi MM, Jasinska-Myga BMP, Wider CM, Vilarino-Guell CP, Ross OP: A comparative study of LRRK2, PINK1 and genetically undefined familial Parkinson disease. J Neurol Neurosurg Psychiatry 2010;81:391-395 
10 Change N, Mercier G, Lucotte G: Genetic screening of the G2019S mutation of the LRRK2 gene in Southwest European, North African, and Sephardic Jewish subjects. Genet Test 2008;12:333-339.

- 11 Lesage S, Leutenegger AL, Ibanez P, Janin S, Lohmann E, Durr A, et al: LRRK2 haplotype analyses in European and North African families with Parkinson disease: a common founder for the G2019S mutation dating from the 13th century. Am J Hum Genet 2005;77:330-332.
-12 Zabetian CP, Hutter CM, Yearout D, Lopez AN, Factor SA, Griffith A, et al: LRRK2 G2019S in families with Parkinson disease who originated from Europe and the Middle East: evidence of two distinct founding events beginning two millennia ago. Am Hum Genet 2006;79:752-758.

13 Warren L, Gibson R, Ishihara L, Elango R, Xue Z, Akkari A, et al: A founding LRRK2 haplotype shared by Tunisian, US, European and Middle Eastern families with Parkinson's disease. Parkinsonism Relat Disord 2008;14:77-80.

14 Chaabani H, Cox DW: Genetic characterization and origin of Tunisian Berbers. Hum Hered 1988;38:308-316.

15 Chaabani H, Sanchez-Mazas A, Sallami SF: Genetic differentiation of Yemeni people according to rhesus and Gm polymorphisms. Ann Genet 2000;43:155-162.
16 Abdennaji GB, Loueslati BY, Buhler S, Hmida S, Ennafaa H, Khodjet-Elkhil $\mathrm{H}$, et al: HLA class II genetic diversity in southern Tunisia and the Mediterranean area. Int J Immunogenet 2006;33:93-103.

17 Ennafaa H, Amor MB, Yacoubi-Loueslati B, Khodjet el-khil H, et al: Alu polymorphisms in Jerba Island population (Tunisia): comparative study in Arab and Berber groups. Ann Hum Biol 2006;33:634-640.

18 Farrer MJ, Gibson R, Hentati F: The ancestry of LRRK2 Gly2019Ser parkinsonism (authors' reply). Lancet Neurol 2009;7:770. 